\title{
THE METHODOLOGY FOR DEFECT QUANTIFICATION IN CONCRETE USING IR THERMOGRAPHY
}

\author{
Bojan MILOVANOVIĆ, Ivana BANJAD PEČUR, Nina ŠTIRMER \\ Department of Materials, Faculty of Civil Engineering, University of Zagreb, \\ Kačićeva 26, HR 10000 Zagreb, Croatia
}

Received 04 Feb 2016; accepted 26 Apr 2016

\begin{abstract}
This paper presents a procedure for detecting and quantifying defects in reinforced concrete structures by using the method of active infrared thermography (IRT). For quantitative analysis, a methodology of thermal stimulation of concrete specimens and post-processing of the gathered data was developed. Presented methodology uses principles of step heating (SH) thermography, pulsed phase (PPT) thermography, principal component thermography (PCT) and correlation operators technique. A short descriptions of the post-processing methods used in the research is also provided in the paper. All three post-processing methods i.e. PPT, PCT and correlation operators technique have shown the possibility to enhance the defect detection in concrete structures in comparison to raw thermograms. According to the data accessible to the authors, in presented research, correlation operators and PCT post-processing techniques are being successfully used for the first time for defect detection within concrete structures. The results of the research clearly show the possibility of using active IRT for the detection and assessment of defect depth (quantification) in reinforced concrete structures with the measurement error within $10 \%$.
\end{abstract}

Keywords: testing methodology, defect characterization, IR thermography, non-destructive testing, reinforced concrete, active thermography techniques, principal component thermography, correlation operators technique.

\section{Introduction}

Over the past few years, many techniques have been developed in order to evaluate the state of reinforced concrete (RC) structures, to detect the location and the extent of construction defects or damaged zones in a non-destructive (NDT) way (Malhotra, Carino 2004; Gorzelańczyk et al. 2013; Lee, Kalos 2015). The use of infrared thermography (IRT) as a means of structural health monitoring has significantly increased in recent years, due in large part, to the advancement of IR cameras and the considerable reduction in their cost. The development of an IR imaging system for RC in-situ applications poses challenges that are not present in many other applications. A practical IRT system for imaging of RC structures should be portable, rugged, and easily adaptable to a variety of geometries. In addition, the properties of material make it particularly difficult to image concrete, which has low thermal conductivity and is thermally inert. This means that it takes a lot of energy to manipulate temperature change of RC structures, i.e. initiate heat flow in order to use active IRT to detect and/or characterise defects. When using IRT, one has to consider also the dimensions of RC structures as well as defects occurring in such structures.
IR thermographic investigation techniques are based on the fundamental principle that subsurface anomalies in a material affect the heat flow through that material. These changes in heat flow cause localized differences in surface temperature during the transient heating and/ or cooling phase where an IR camera monitors the surface temperature variation (Malhotra, Carino 2004). The only precondition for detection is that defects in the object under examination should lead to a sufficient variation of thermal properties compared to the bulk material (Maierhofer et al. 2007).

Active IRT is being used extensively to quantify defects in metals and composite materials in which IRT offers some advantages over other methods (Ibarra-Castanedo et al. 2007). The method has proved to be very useful for the determination of defect's location in $\mathrm{RC}$ structures where in most cases the sun has been used as a natural heat source (ASTM D-4788:2003; Dumoulin, Averty 2012). Using the sun as a heat source (passive thermography) is dependent on factors like clouding, time of the year, etc. as well as whether the area under investigation is in the shadow of not. This significantly limits the possible use of passive thermography in NDT. Artificial

Corresponding author: Bojan Milovanovic

E-mail: bmilovanovic@grad.hr 
heating using halogen lamps and/or IR heater as a thermal excitation for defect detection in concrete structures has been used by Weritz et al. (2005), Maierhofer et al. (2006), Kurita et al. (2009). While there have been a lot of studies of detecting defects in RC structures, the problem of defect quantification in RC structures was tackled by only few researchers (Maierhofer et al. 2005, 2007; Meola et al. 2005). These researchers studied mainly the possibilities and the influence of concrete properties on defect detection in concrete and masonry structures, all based on the observation of thermal contrast. The applicability and limitations of void and delamination detection below concrete cover, using active IRT (thermal contrast and phase contrast evaluation techniques), have been studied experimentally by Cotič et al. (2015). The main result of the work performed by Cotič et al. (2015) is the detectability graph from which it is evident that by applying the thermal contrast method, it is possible to detect defects only if the defect is covered by a layer of concrete cover having a thickness of $0.9 \times$ diameter, or less. On the other hand, by applying the phase contrast method, it is possible to observe defects beneath somewhat deeper layers of concrete, $\approx 1.3 \times$ diameter (Cotič et al. 2015). By using an active IRT, Dumoulin et al. (2010) attempted to estimate the defect depth, for which they used a direct relationship between the depth of a defect and the thermal diffusion length, encompassing an empirical constant and a blind frequency of the phase, which resulted with significant error between the real and calculated defect depth. On the other hand there were attempts to solve an inverse problem in order to quantify defects in concrete structures (Weiser et al. 2010). Weiser et al. (2010) are careful with the conclusions and state only that increased reliability for quantitative prediction of data is possible. It was noticed by the authors during literature review that there is no established methodology for determining defect's size by using active IRT in the field of concrete structures. Thus, the possibility of active IRT application to $\mathrm{RC}$, development of testing methodology and analysis procedures that enable defect quantification is being presented in this paper.

\section{Experimental work}

The experimental setup for the performance of IRT measurements is shown in Figure 1a. It consists of a thermal excitation unit, an IR camera and a computer system that enables digital data recording in real time. In this paper the results of the following experimental setup will be presented, the research was conducted by using reflecting method (Fig. 1a), where surface temperature was monitored during 60 minute heating period and cooling period lasting additional 60 minutes. This heating period resulted with the maximum thermal contrast, while the cooling period enabled the specimen to cool down to the ambient temperature. During the research other experimental setups were also tested, the results of which will be published elsewhere. Throughout the testing period, the ambient temperature in the laboratory was kept between 18.3 and $21.0{ }^{\circ} \mathrm{C}$, while the measured reflective temperature was between 22.5 and $24.7{ }^{\circ} \mathrm{C}$. The controlled conditions, which were created, mean that there was no mirror like reflection sources on the specimen's surface, while the influence of diffuse reflections (which cannot be avoided) was compensated by measuring the reflective temperature on the specimens' surface.

Thermal excitation was performed using $1000 \mathrm{~W}$ halogen lamp, where heating distances were 1.5; 2.0 and $3.0 \mathrm{~m}$ from the surface of concrete specimens, respectively. The specimens are large enough $(50 \times 50 \times 10 \mathrm{~cm})$ to be able to simulate real defects, without the influence of edges or defects between themselves on the temperature field.

Schematic drawings of the test specimens, with its dimensions, size and location of the embedded defects are shown in Figures $1 b-d$, where $d$ is the thickness of the defect, while $\Phi$ is the diameter of the defect. Three types of concrete specimens with known defects were prepared where defect size, embedment depth and thickness were varied in order to determine the influence of geometric properties and defect's depth on the possibility of detection by means of using IRT. In Figure $1 b$, defects 1,2 , 5 and 6 all have the same thickness $(40 \mathrm{~mm})$, are at the same depth (20 and $40 \mathrm{~mm}$ depending on the side of the specimen), but their diameter varies, on the other hand defects 3, 4 and 7 have the thickness $(20 \mathrm{~mm})$ and are at the same depth (30 and $50 \mathrm{~mm}$ depending on the side of the specimen), while the diameter again varies. For specimen BM x-2, all defects have the same diameter $(50 \mathrm{~mm})$ but their thickness and depth varies as shown in Figure $1 \mathrm{c}$, in order to test the detectability of the defects depending on their thickness and the depth. Specimens BM X-3 show the effect of reinforcement on the detectability of defects, Figure 1d, and also test whether there is the possibility to detect sharp edges of defects. The following notation system has been adopted for the specimen identification, BM x-y, where " $\mathrm{x}$ " indicates the concrete mix while " $y$ " indicates the arrangement of defects embedded into the specimens, Figures $1 \mathrm{~b}-\mathrm{d}$, and Table 1. The label of the particular defect within the specific arrangement is given in Figures $1 \mathrm{~b}-\mathrm{d}$ as well as any other thermogram, correlogram, phasegram or EOF, respectively. Thus, the reader can connect the concrete mix, the arrangement of the defects and the specific defect that is being discussed further in the paper. The concrete mixtures created in this research simulate three types of concrete that can be found in real structures, differing in their compressive strength, air content and in their thermal properties, Table 1. The concrete mixtures and testing procedures used to determine properties of concrete (Table 1) are published elsewhere (Milovanović 2013).

For simulating compaction defects and voids in concrete, defects made of polystyrene foam have been fastened and carefully embedded into fresh concrete speci- 
a)
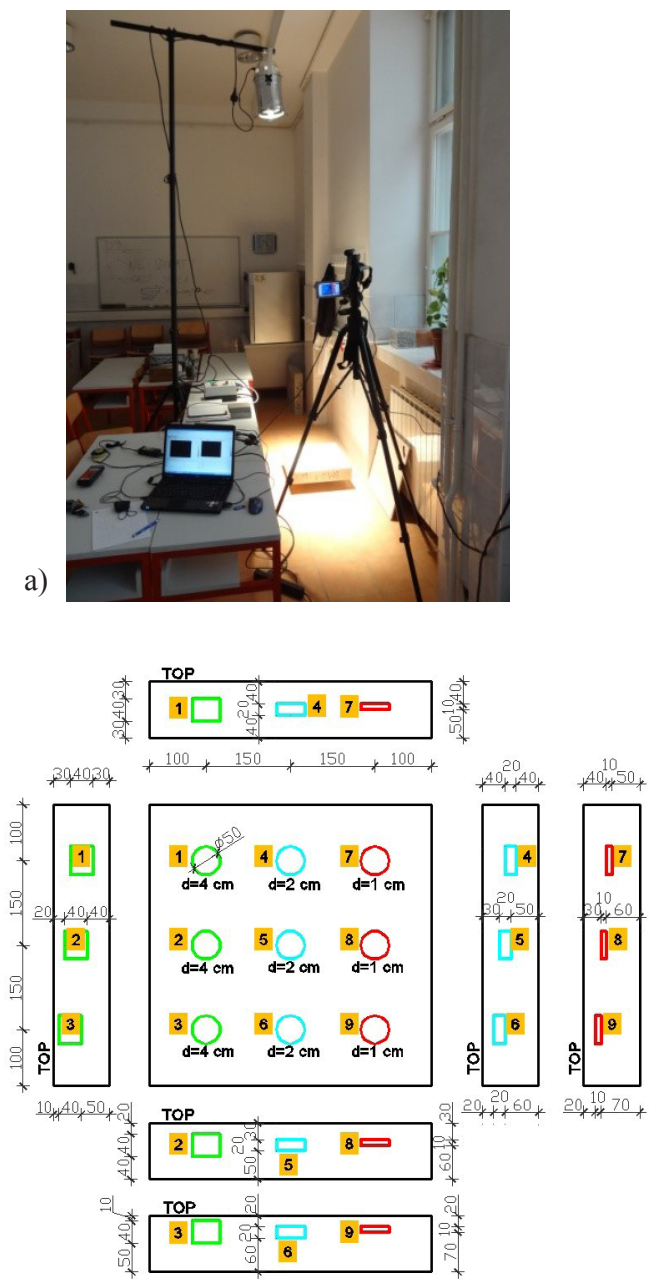

b) $\mathrm{BM} \mathrm{x}-1$

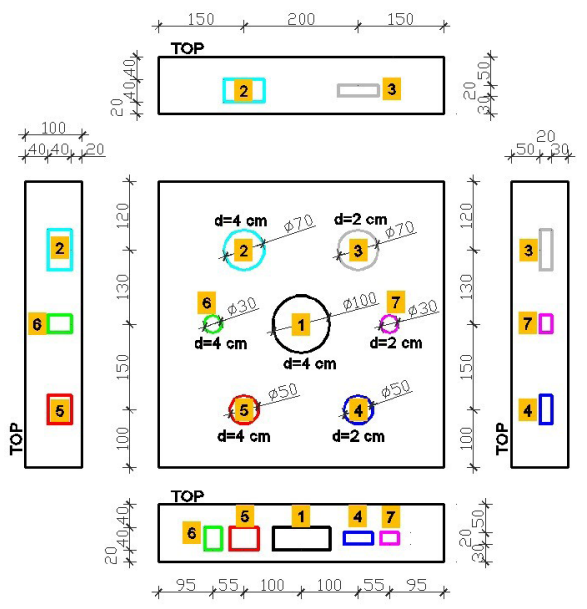

c) $\mathrm{BM} x-2$

Fig. 1. a) Thermal excitation of the object under examination using IRT, (image by authors); b)-d) Schematics of the arrangement of defects in concrete test specimens with polystyrene defects, dimensions in $\mathrm{mm}$

Table 1. Properties of concrete used for creating test specimens

\begin{tabular}{|c|c|c|c|}
\hline \multirow{2}{*}{ Property tested } & \multicolumn{3}{|c|}{ Concrete mixture } \\
\hline & BM 1-y & BM 2-y & BM 3-y \\
\hline $\begin{array}{l}\text { Concrete density }\left[\mathrm{kg} / \mathrm{m}^{3}\right] \\
2194.0\end{array}$ & & 2382.7 & 2545.6 \\
\hline Air content $[\%]$ & 10.5 & 4.6 & 1.4 \\
\hline Compressive strength [MPa] & 18.93 & 40.99 & 89.05 \\
\hline Thermal conductivity $[\mathrm{W} / \mathrm{mK}]$ & 1.73 & 2.21 & 2.80 \\
\hline Thermal diffusivity $\left[\mathrm{m}^{2} / \mathrm{s}\right]$ & $7.996 \times 10^{-7}$ & $9.074 \times 10^{-7}$ & $11.14 \times 10^{-7}$ \\
\hline Emissivity & 0.928 & 0.957 & 0.958 \\
\hline
\end{tabular}

mens in order to obtain the intended depth. Within the specimens BM $\mathrm{x}-3$, defects were positioned underneath the reinforcement with different rebar spacing, while the specimens BM x-1 and BM x-2 do not have any reinforcement. All the specimens were tested from both sides, in order to gather data for as much as possible embedment depths, together with the need to determine the influence of reinforcement on the test results in case of specimens BM X-3.
To perform experiments presented in this paper, IR camera FLIR ThermaCAM P640 with spectral range from 7.5-13 $\mu \mathrm{m}$, thermal sensitivity (NETD) $60 \mathrm{mK}$ was used. The IR camera detector is Focal Plane Array (FPA) detector consisted out of $640 \times 480$ individual detectors. The IR camera was connected to the computer and the thermal excitation using the active thermography electronic interface. During the pre-processing, using FLIR ThermaCAM $^{\mathrm{TM}}$ Researcher Pro 2.9 software, and Mat- 
Lab a series of more than 700, 2D thermograms were converted into a sequence. Thus, an array i.e. 3D matrix was created, where rows and columns are rows and columns of thermogram and the third dimension gives the temperature change of a pixel in time. Figure 2 presents optimal thermograms taken from the thermogram sequences after step heating $(\mathrm{SH})$ thermography was used to collect sequences of thermograms. These thermograms represent raw data that was gathered using this system, at the time frame when the temperature difference between defected and sound area was the greatest.

It is evident from presented thermograms (Fig. 2) that no defects can be located with a sufficient amount of certainty, since uneven heating, and reflectance influence the measurements. Due to the fact that optimal thermograms (Fig. 2) cannot be used for the location of defects (especially not for small defects), it is clearly visible that post-processing of the thermogram sequences needs to be performed. Pulsed phase thermography (PPT), principal component thermography (PCT) and correlation operators' techniques were the post-processing techniques used to determine the existence of defects in concrete specimens.

\section{Post-processing techniques}

Defect detection and quantification is rarely a straightforward procedure because of all the signal degradation sources. Pre-processing by traditional image enhancement techniques may help to increase defect/non-defect contrast. However, techniques that are more sophisticated are often required. In the following text, three different techniques for thermogram sequence post-processing aimed to increase defect/non-defect contrast are being shortly described. These post-processing techniques are widely known in the field of NDT of metal, honeycomb and other composite materials, and except PPT, they are exclusively used in mechanical engineering and aerospace industry.

PPT is an active IR technique which enables the collected data to be transformed from the time domain to the frequency domain using 1D discrete Fourier transform (DFT) (Maldague 2001). Discrete frequencies " $f_{n}$ " for which phase delay (phasegrams) and amplitude (ampligrams) images can be reconstructed are given with the
Eqn (1) where $n$ is the observed thermogram, $N$ is the total number of thermograms in the sequence, while $\Delta$ is the sampling interval:

$$
f_{n}=\frac{n}{N \Delta} .
$$

PCT used for processing IR sequences is based on thermal contrast evaluation in time, while the PCT analysis is based on the second order statistics of IR image data. The thermograms sequence containing the information about the specimen is processed using singular value decomposition (SVD) based PCT. The 3D image matrix is converted to $2 \mathrm{D}$ matrix as described in Parvataneni (2009). Results of the PCT are empirical orthogonal functions (EOF) constructed from a set of orthogonal statistical modes that provide the strongest projection for the data. In the IR context, the correlation coefficient refers to the strength and direction of the linear relationship between a given temperature evolution reference and the temperature evolution of all pixels of the specimen under inspection (Klein et al. 2008). Correlograms are constructed by comparison of temperature evolution of one pixel of the thermogram with the evolution of reference temperature of the thermogram sequence.

Contribution of this paper is that PCT and correlation operators' techniques are alongside PPT adopted for the use in the field of RC structures, within the newly developed methodology for defect characterization in concrete using active IRT.

\section{Results of experimental research}

As shown in Figure 2, it is very difficult to use thermograms gained after SH thermography for the detection of defects within concrete structures, due to primarily the uneven heating and reflectance issues. Thus in this chapter, described post-processing techniques were used for determining the existence of defects within concrete specimens. The figures presented in this chapter (Figs 3-8) are selected representative correlograms, EOF's and phasegrams, respectively.

These figures represent specific specimen configuration, as shown in captions, for the sole purpose to depict trends that occurred during the research. The presented trends can be generalised to other specimen configura-
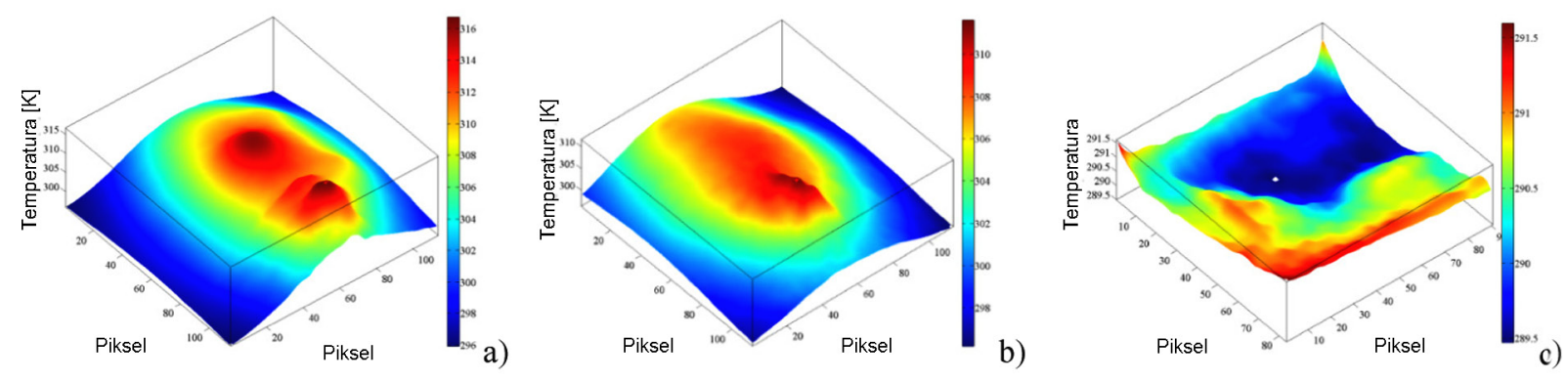

Fig. 2. Optimal thermograms of selected configurations: a) BM 3-1 bottom surface, distance 1.5 m; b) BM 2-2, bottom surface, distance $1.5 \mathrm{~m}$; c) BM 1-3, top surface, distance $3 \mathrm{~m}$ 
tions. It was found in this research that the distance of the excitation source from the specimens' surface does influence the possibility of defect detection in a way that more uniform heating of the specimens is recorded with greater the distance. At the same time, due to the lower contrast between the defective and non-defective (sound) area, the detectability is lower.

\subsection{Correlation operators' technique}

In the correlograms (Figs 3 and 4) defects are being manifested in such a manner that defect edge is defined by the significant decrease of the statistical correlation operator. In general, defects are encircled with the area of low value of correlation operator, while their centres are of high correlation operators' values. Using correlation operators as a post-processing technique for the thermogram sequence, defects of $10 \mathrm{~cm}$ in diameter at the depth of $40 \mathrm{~mm}$ can be detected at the maximum distance of the excitation system of $3 \mathrm{~m}$. The existence of reinforcement between the specimen's surface and the defect decreases the detectability of defects (Figs 3 and 4). This is due to the more significant lateral heat transfer in the specimen when there is reinforcement between the specimen's surface and the defect (Fig. 4), compared to the specimen without the reinforcement (Fig. 3). Lateral heat transfer decreases the temperature contrast between the defected and sound area of the specimen, masks the defect and decreases its detectability, as is the case with the defect no.2 of the specimen BM 1-3 (bottom surface, distance of $2 \mathrm{~m}$ ) (Fig. 3) which is located under the reinforcement with more dense spacing between bars.

\subsection{Principal component thermography (PCT)}

Regarding the PCT, it proves to be very useful for detecting small effects. It has to be said that one needs to be careful with the interpretation of single EOF, without looking at other EOF's that resulted from the PCT of the thermogram sequence. The characteristic property of the PCT is that it can produce EOF's with perfect contrast between defected and sound area (Figs 5 and 6), while the following EOF can provide only noise, which can mislead into the conclusion of the defect free area.

Additionally, the reflection is not being removed from certain EOF's by the PCT, which means that EOFs containing reflection from excitation source can be misinterpreted. Nevertheless, the reflection can be identified by looking at the sequence of EOFs, since the reflection pattern will change significantly in different EOFs while the defects pattern will change only slightly. It was noticed that in case of large defects (specimens BM x-3) one can only use first few EOFs. Unlike that, when smaller defects are observed (specimens denoted as BM x-1 and $\mathrm{BM} \mathrm{x}-2$ ) one can detect defects in a larger number of EOFs. This can be an advantage since by analysing more EOFs, one can rule out the reflections and uneven heating of the specimens.

By post-processing of thermogram sequences using PCT, some of the defects were successfully detected in the specimens BM 2-2 and BM 3-2 when bottom surface was tested at the excitation source distance of $1.5 \mathrm{~m}$. This is important because these are the configurations of the specimens BM x-2 for which defects could be detected only by using PCT technique (see Figs 9-11).

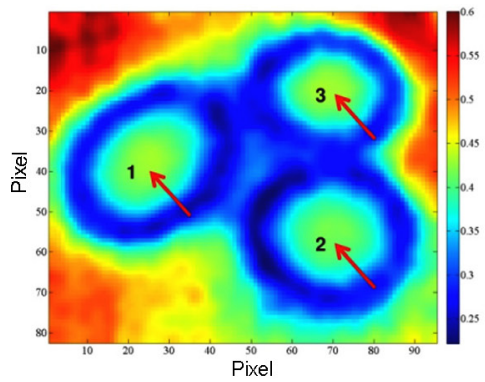

Fig. 3. Correlogram, BM 1-3, bottom surface, distance $2 \mathrm{~m}$

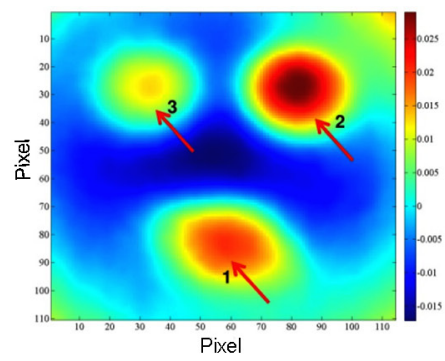

Fig. 6. PCT $\left(\mathrm{EOF}_{3}\right), \mathrm{BM} 3-3$, bottom surface, distance $1.5 \mathrm{~m}$

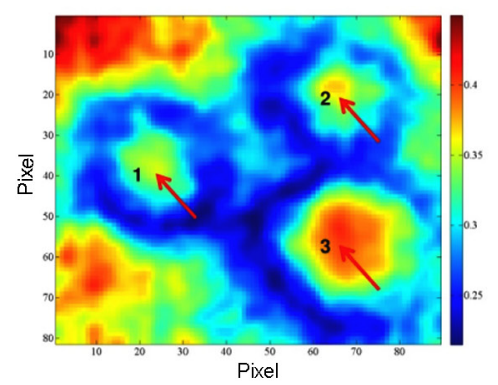

Fig. 4. Correlogram, BM 1-3, top surface, distance $2 \mathrm{~m}$

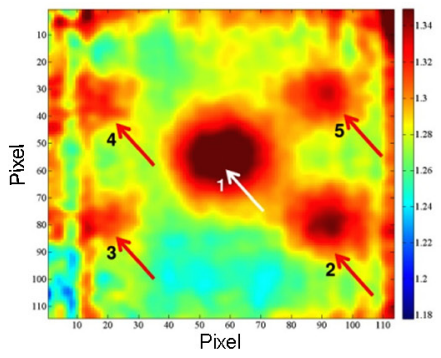

Fig. 7. Phasegram, BM 3-1, bottom surface, distance $1.5 \mathrm{~m}\left(f=1.377 \times 10^{-3} \mathrm{~Hz}\right)$

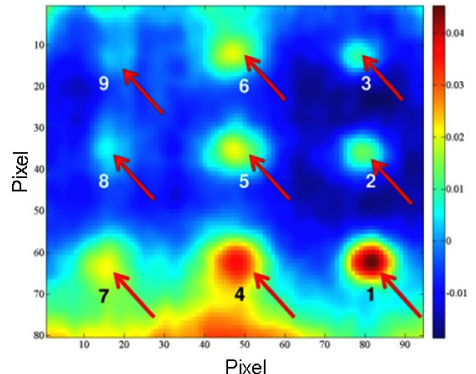

Fig. 5. PCT $\left(\mathrm{EOF}_{2}\right)$, BM 3-2, top surface, distance $2 \mathrm{~m}$

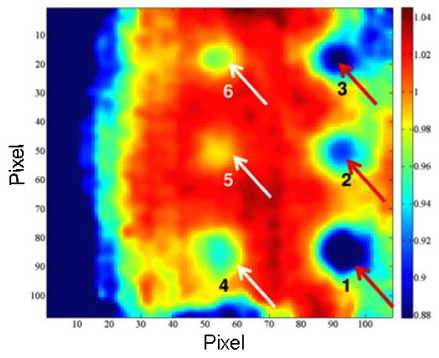

Fig. 8. Phasegram, BM 3-2, top surface, distance $1.5 \mathrm{~m}\left(f=4.525 \times 10^{-4} \mathrm{~Hz}\right)$ 


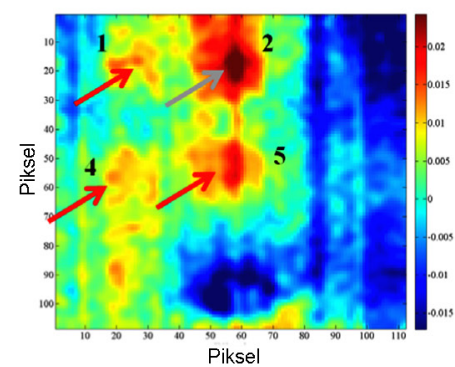

Fig. 9. PCT $\left(\mathrm{EOF}_{5}\right)$, BM 3-2, bottom surface, distance $1.5 \mathrm{~m}$

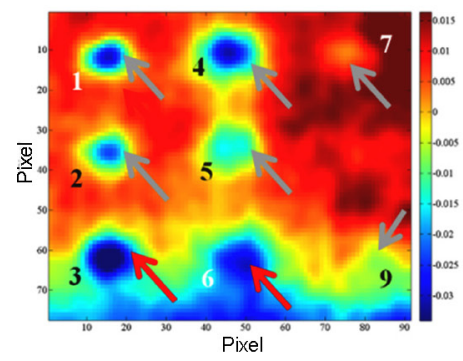

Fig. 12. PCT $\left(\mathrm{EOF}_{2}\right), \mathrm{BM} 1-2$, top surface, distance $2 \mathrm{~m}$

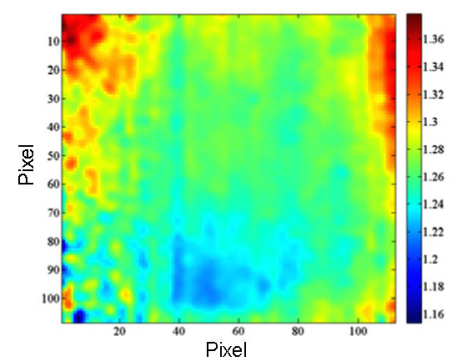

Fig. 10. Phasegram, BM 3-2, bottom surface, distance $1.5 \mathrm{~m}\left(f=1.169 \times 10^{-3} \mathrm{~Hz}\right)$

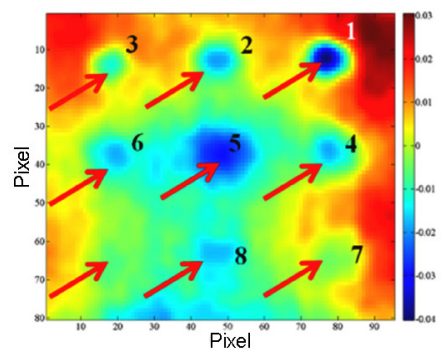

Fig. 13. PCT $\left(\mathrm{EOF}_{2}\right), \mathrm{BM} 2-2$, top surface, distance $2 \mathrm{~m}$

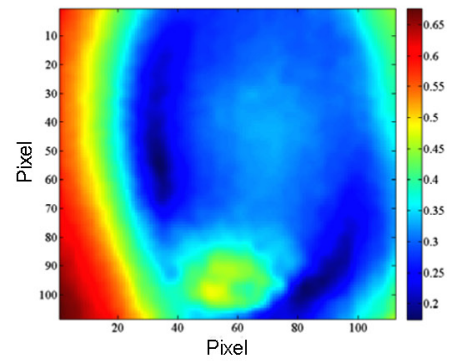

Fig. 11. Correlogram, BM 3-2, bottom surface, distance $1.5 \mathrm{~m}$
Concrete quality, measured through its compressive strength, has an influence on the detectability of defects when using PCT, as shown in Figures 12-14. This can be explained by the fact that due to the low thermal conductivity, thermal waves could not reach the defect and return back to the surface in the time faster than the duration of thermal excitation of the specimen. On the other hand, due to the high thermal conductivity in case of a concrete of very good quality and dense structure, lateral diffusion on the specimen's surface is dominant and it masks the thermal wave reflecting from the defect inside the specimen and thus prevents the defect detection.

\subsection{Pulsed phase thermography (PPT)}

Regarding the post-processing using the DFT, it was noted that sufficient phase contrast exists for the defects to be detectable in the frequency spectra (Figs 7 and 8). Additionally, an optimal frequency exists for which the phase contrast is the highest, and for which the noise content is reduced to a minimum, while at higher frequencies, noise increases and defects are no longer visible in phasegrams. Figures $15 \mathrm{a}-15 \mathrm{~b}$ show the phase spectra and phase contrast plot for the defect area (Defect 1 of the specimen BM 3-1, as shown in Figs 1 a and 7), where the phase contrast is more visible in the log scale (Fig. 15b).

Since the non-uniform surface heating is an inherent source of uncertainty in IRT, one of the most important result of the post-processing is the fact that EOFs and phasegrams are practically unaffected by non-uniform heating.
It can be concluded that by following the described procedure, defects of the minimum diameter of $50 \mathrm{~mm}$ can be detected at the thermal excitation distance of $2 \mathrm{~m}$ if defects are at the depth of $3 \mathrm{~cm}$ and of thickness of $1 \mathrm{~cm}$.

If the dependency of concrete quality and the existence of the reinforcement between the specimen's surface and the defect is being analysed, it can be concluded that one can always find the optimum frequency with the best phase contrast and minimum noise on the phasegrams. This frequency changes in such manner that at this point of the research, the authors could not get any correlation between the concrete quality and the reinforcement and their influence on the optimum frequency.

\section{Defect depth model}

Defect depth was calculated using the Eqn (2), which is an expression derived from the solution for a heat flux of finite duration impinging on the front side of a plate of finite thickness (Ringermacher et al. 1998), where $\alpha_{\text {diff }}$ is thermal diffusivity of concrete, $C_{x}$ is calibration coefficient for the observed time period from beginning of the measurement. It has to be said that the model proposed in Eqn (2) was chosen for defect quantification by using empirical approach, since the authors introduced the calibration coefficient $C_{x}$ to take into account the differences of the analytical solution and the assumptions of the 1D model (Ringermacher et al. 1998) and 3D heat flow that actually occurs in the concrete specimens:

$$
\alpha_{\text {diff }}=\frac{C_{x} \cdot L^{2}}{\pi^{2} \cdot t_{x}}
$$




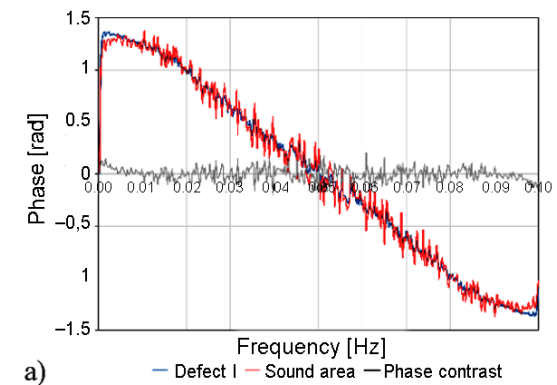

Fig. 15. Phase spectra of transient curves, BM 3-1, bottom surface, distance $1.5 \mathrm{~m}$; a) linear scale, b) logarithmic scale

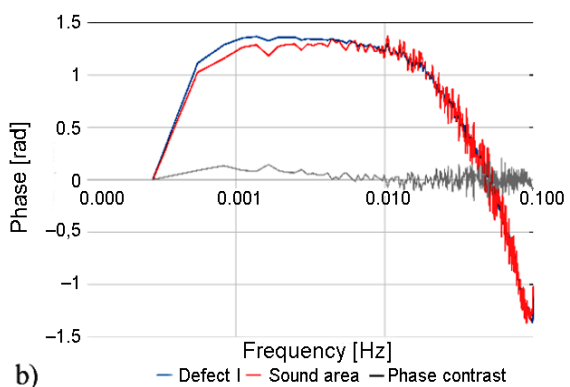

b)

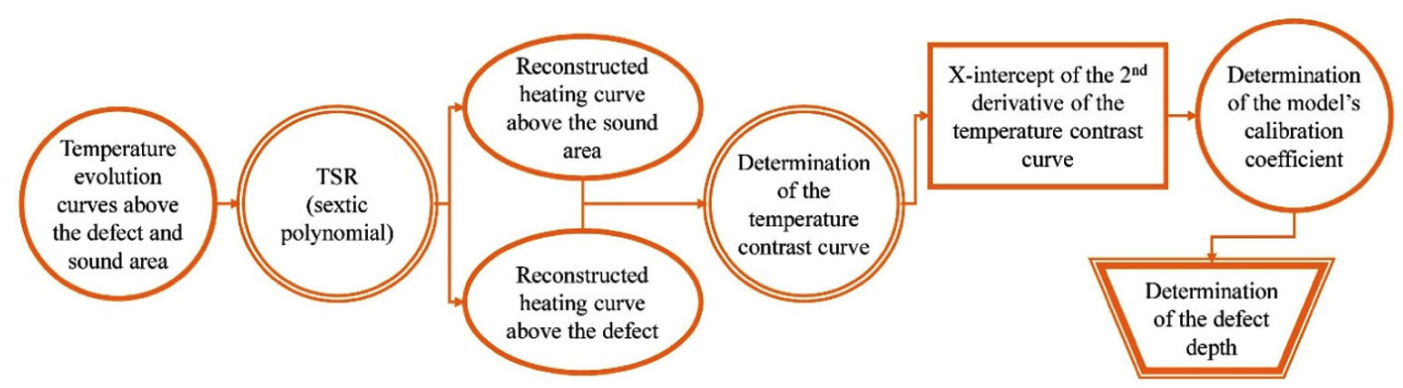

Fig. 16. Block diagram for the process of defect depth determination

where, the time of occurrence of inflection point on the thermal contrast curve is being observed. Therein, instead of specimen thickness $L$ defect depth $D$ was introduced. Determination of defect depth from the sequence of thermograms according to the model used is described using a block diagram (Fig. 16). Further in the text, an example of the defect depth for the specimen BM 2-3 will be described. The same principle can be applied for any other defect or specimen configuration.

The temperature evolution curve (temperature profiles) above the defect no.1 in the specimen BM 2-3 (bottom surface, distance $2 \mathrm{~m}$ ) are shown in Figure 17. Temperature evolution curve above the sound area (immediately next to the defect no.1) and the thermal contrast evolution curve for the defect no.1, respectively, are shown in Figure 17. Characteristic points of the thermal contrast evolution curve that are being used for the determination of the defect depth, defect no.1 in the specimen BM 2-3 (bottom surface, distance $2 \mathrm{~m}$ ) are highlighted in Figure 17.

Inflection point on the thermal contrast evolution curve (temperature profile) is characterised by the time of inflection $t_{\text {infl }}$, which is acquired by the determination of $x$-intercept of the $2^{\text {nd }}$ derivative of the temperature profile. Thermographic signal reconstruction (TSR) was then performed on the part of the temperature profile, which has enabled the differentiation of temperature profile. Sextic polynomials were used to fit temperature profiles in the time interval from the beginning up to $3000 \mathrm{~s}$ of the heating process. Curve fitting for the same time interval was chosen for the analysis because of the fact that in this time interval one can distinguish the defected from the non-defected area of the specimen. Subsequently, the calibration coefficient $C_{i n f l}$ value was determined from the known defect depth and measured thermal diffusivity of concrete, all by using previously determined time of inflection $t_{\text {infl }}$ for the defect in question (defect no.1), specimen BM 2-3 (bottom side, distance $2 \mathrm{~m}$ ):

$$
C_{\text {infl }}=\frac{\alpha_{\text {diff }} \cdot \pi^{2} \cdot t_{i n f l}}{L^{2}}
$$

For the determination of $C_{i n f l}$, specimen BM 2-3 was used, whose bottom surface was analysed (defect no.1), while the thermal excitation was positioned at the distance of $2 \mathrm{~m}$ from the specimen's surface (Fig. 18).

Figure 19 gives the $\mathrm{x}$-intercept of second derivative of the thermal contrast evolution curve, from which the time of inflection of the thermal contrast can be derived. It should be emphasized that one should observe the $\mathrm{x}$-intercept of the first descending part of the $2^{\text {nd }}$ derivative of thermal contrast curve. This is because it was perceived that wrong results could be obtained in cases when the first $\mathrm{x}$-intercept happens on the ascending part of the second derivative curve. By following the described procedure, the calibration coefficient was calculated as $C_{i n f l}=4.8$. This was done in such a manner that the average values of the measuring results were close to the known value of the defect depth as designed for the observed defect. 


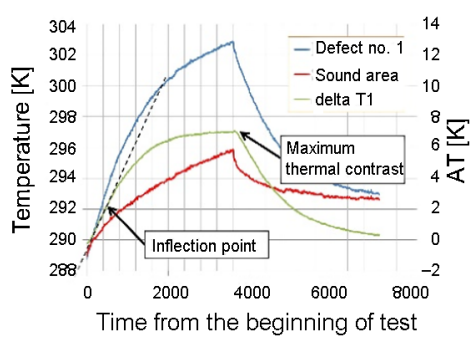

Fig. 17. Temperature evolution curves, bottom side, specimen BM 2-3, distance $2 \mathrm{~m}$

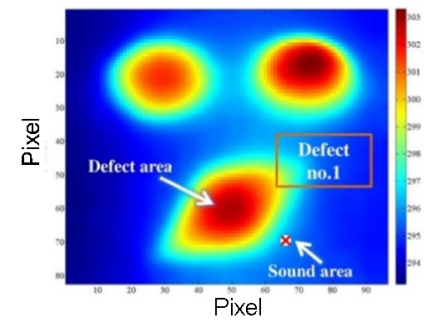

Fig. 18. Optimal thermogram; BM 2-3, bottom side, distance $2 \mathrm{~m}$

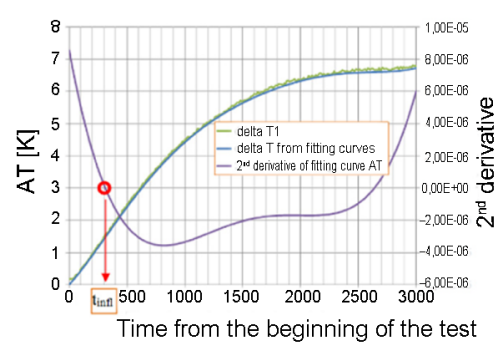

Fig. 19. $2^{\text {nd }}$ derivative of the thermal contrast evolution, bottom side, specimen BM 2-3, distance $2 \mathrm{~m}$

\section{Defect depth measurement}

Using Eqn (4) and the calculated calibration coefficient ( $C_{\text {infl }}=4.8$ ), defect depth $D$ in other specimens and for any heat source distance can be determined. The only prerequisite for the calculation of defect depth is that thermal diffusivity $\alpha_{\text {diff }}$ of the sound material (non-defected concrete) is known. Time of inflection $t_{\text {infl }}$ has to be determined for every specimen and every defect observed, as described in previous chapter and Figure 16. Thermal diffusivity used for calculation of defect depth is shown in Table 1:

$$
D=\sqrt{\frac{\alpha_{\text {diff }} \cdot \pi^{2} \cdot t_{\text {infl }}}{4.80}} .
$$

When a measurement error is determined, defect depth measurements can then be performed using a described method. The measurement should be performed using several different points that are close enough to the observed defect, i.e. several temperature evolution curves of concrete sound area should be extracted and then analysed. Additionally, one can perform multiple measurements on the same specimen, either from the same or from several different excitation source distances. Furthermore, the thermogram acquisition process should be done when the specimen is cooled to the ambient temperature. Table 2 shows the average depth for defects no.1, no. 2 and no. 3 of the specimen BM x-3, where this average defect depth was calculated from measured defect depths for each of three types of concrete used in this research (as described in Table 1). Additionally, Table 2 shows the deviation of the measured average defect depth from the designed values.

The distances of excitation source from the specimens' surface were taken as 1.5, 2 and $3 \mathrm{~m}$, respectively. It was established that measured results deviate at most by $10.9 \%$ from the known (designed) defect depth for specimens $\mathrm{BM} \mathrm{x}-3$, at all configurations of measurements (Table 2). It can also be seen that measured values of defect depth concur with designed values for all three distances of the heating source.

The difference between the designed and measured values of defect depth has likely been created by the error in determining the thermal diffusivity of concrete and/or
Table 2. Average defect depth for the specimen BM x-3

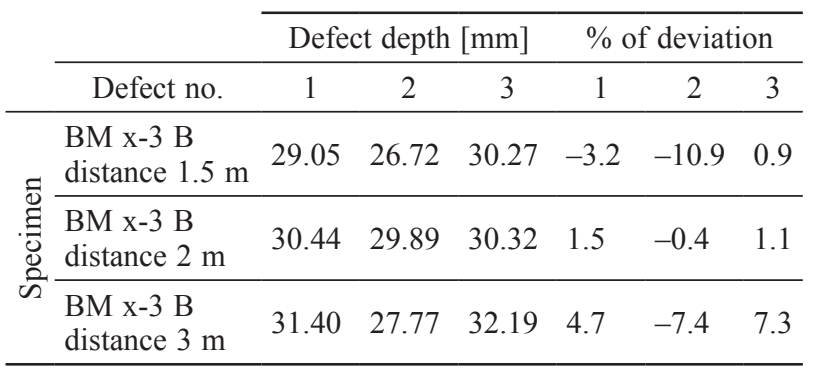

by the slight shift of the defects when specimens were casted. Furthermore, significant influence on the accuracy of the defect depth has the point on the non-defected area of the specimen for which temperature evolution curve was acquired. This implies that measurement results are influenced by the subjective decision of the researcher.

It is of crucial importance that the point representing the defect is taken in the centre of the defect area while the points representing the non-defected area are taken as close as possible to the defect, but at the same time far enough to be able to eliminate the influence of lateral heating. The reflection and emissivity changes, which both result in an apparent change of the temperature field on the specimen's surface, should also be avoided when doing in-situ measurements using the presented methodology. If the reinforcement exists between the defect and the specimen's surface, a new calibration coefficient $C_{i n f l}^{\prime}$ needs to be determined. This is needed since it was proved that measurement error between $50 \%$ and $93 \%$ could be made if one measures the defect depth with reinforcement between the defect and surface using the calibration coefficient $C_{\text {infl }}=4.8$.

If one follows the same calibration procedure as presented in chapter 0 of this paper, new calibration coefficient $C_{\text {infl }}^{\prime}=11.5$ can be obtained, which is then incorporated in equation 4 and used to determine the defect depth in cases when there is reinforcement between the defect and specimens' surface. The analysis was performed for the top side of the specimens BM x-3 where the average defect depth was calculated from the measured defect depth for each type of concrete, and for three distances of the excitation source, 1.5, 2 and $3 \mathrm{~m}$ respectively. It was established that for specimens BM x-3, measured results 
deviate at most by $9.9 \%$ from the designed defect depths, at all measurement configurations.

\section{Conclusions}

Results of the research using the method of active IRT presented in this paper are such that the following can be concluded. Active IRT can be used contactless to give direct or processed images of the surface detecting the defects within the concrete structures. A quantitative analysis of the experimental data can be carried out in order to characterize the defects, all by using the methodology presented in this paper. Physical and mechanical properties of concrete influence the test results, but it was shown here that with the understanding of characteristics of the measurement system, test configuration, and thermal properties of concrete, it is possible to characterize defects using IRT. During the research, three post-processing methods were used i.e. PPT, PCT and correlation operators technique which all proved to be advancing the possibility of detecting defects in concrete structures in comparison to raw thermograms. Generally, it can be concluded from the presented research, that if one uses the $1000 \mathrm{~W}$ thermal excitation system at a maximum distance of $3 \mathrm{~m}$, as the one presented in this research, defects of $100 \mathrm{~mm}$ in diameter on the depth of $40 \mathrm{~mm}$ can be detected with high certainty. Even smaller defects can be detected when combining several post-processing methods. Although the authors set some limitations in the text above, it has to be said that in case of larger defects (diameter and/or thickness) one could detected them at greater depths by using the same excitation system. On the other hand, if one uses more powerful excitation source, it would contribute to the possibility of defect detection and heating duration could be shorter, all in respect to the defect size and depth. However, when performing the in-situ testing, one has to decide on the feasible excitation source power, as well as the duration of heating for the expected defects.

Correlation operators and PCT post-processing techniques are still relatively non-investigated techniques in terms of detecting the existence of defects by using IRT. According to the data accessible to the authors, in this paper, these two techniques are being successfully used for the first time for detecting defects within concrete structures. Correlation operators' technique is interesting due to the simplicity of use and the fact that there is no need for the definition of any specific parameters for the calculation.

In this paper, the methodology of determining the defect depth was defined, and the model for determining defect depth was established. This model is based on the theoretical assumptions of heat conduction through the material after the stimulation with the Dirac pulse, but it can be said that the defect depth was determined based on the empirical approach when one takes into account the test setup and procedure used in this research. The model requires the knowledge of the inflection time of the temperature contrast evolution curve, thermal diffusivity of concrete as well as the coefficient of calibration. The average values of measured defect depths for all thermal excitation distances proved to be in a good correspondence with designed defect depths, where the deviation was within the limits of $\pm 10 \%$. Additional research needs to be performed in order to refine the proposed model and also to include defect thickness determination in the quantification procedures. Furthermore, it is important to conduct additional research in order to prove the applicability of IRT for detecting natural anomalies (delaminations, corrosion, cracking and concrete degradation) in existing structures to prove the accuracy and reliability of the IRT.

\section{Funding}

The research was performed within a research project 082-0822161-2990 "From Nano to Macro-structure of Concrete", funded by Croatian Ministry of Science, Education and Sports.

\section{Disclosure statement}

The authors declare that they have no competing financial, professional, or personal interests from other parties.

\section{References}

ASTM D-4788:2003. Standard test method for detecting delaminations in bridge decks using infrared thermography. ASTM Standard.

Cotič, P.; Kolarič, D.; Bosiljkov, V. B.; Bosiljkov, V.; Jagličić, Z. 2015. Determination of the applicability and limits of void and delamination detection in concrete structures using infrared thermography, NDT \& E International 74: 87-93. https://doi.org/10.1016/j.ndteint.2015.05.003

Dumoulin, J.; Averty, R. 2012. Development of an infrared system coupled with a weather station for real time atmospheric corrections using GPU computing: application to bridge monitoring, in QIRT 2012 - $11^{\text {th }}$ International Conference on Quantitative InfraRed Thermography, 11-14 June 2012, Naples, Italy.

Dumoulin, J.; Ibarra-Castanedo, C.; Quiertant, M.; Taillade, F.; Bendada, A.; Maldague, X. P. V. 2010. Evaluation of FRP gluing on concrete structures by active infrared thermography, in QIRT 2010 - $10^{\text {th }}$ International Conference on Quantitative InfraRed Thermography, 27-30 July 2010, Québec, Canada.

Gorzelańczyk, T.; Hoła, J.; Sadowski, Ł.; Schabowicz, K. 2013. Methodology of nondestructive identification of defective concrete zones in unilaterally accessible massive members, Journal of Civil Engineering and Management 19(6): 775-786. https://doi.org/10.3846/13923730.2013.812577

Ibarra-Castanedo, C.; Genest, M.; Piau, J.-M.; Guibert, S.; Bendada, A.; Maldague, X. P. V. 2007. Active infrared thermography techniques for the nondestructive testing of materials, Chapter 14 in C. H. Chen (Ed.). Ultrasonic and advanced methods for NDT and material characterization. Singapore: World Scientific Publishing. https://doi.org/10.1142/9789812770943_0014

Klein, M. T.; Ibarra-Castanedo, C.; Bendada, A.; Maldague, X. P. V. 2008. Thermographic signal processing through correlation operators in pulsed thermography, in Thermosense 
XXX, Proc. of SPIE, 18-20 March 2008, Orlando, Florida, USA, vol. 6939.6 p.

Kurita, K.; Oyado, M.; Tanaka, H.; Tottori, S. 2009. Active infrared thermographic inspection technique for elevated concrete structures using remote heating system, Infrared Physics \& Technology 52(5): 208-213. https://doi.org/10.1016/j.infrared.2009.07.010

Lee, S.; Kalos, N. 2015. Bridge inspection practices using nondestructive testing methods, Journal of Civil Engineering and Management 21(5): 654-665.

https://doi.org/10.3846/13923730.2014.890665

Maierhofer, C.; Brink, A.; Röllig, M.; Wiggenhauser, H. 2005. Quantitative impulse-thermography as non-destructive testing method in civil engineering - experimental results and numerical simulations, Construction and Building Materials 19(10): 731-737.

https://doi.org/10.1016/j.conbuildmat.2005.06.002

Maierhofer, C.; Arndt, R. W.; Röllig, M.; Rieck, C.; Walther, A.; Scheel, H.; Hillemeier, B. 2006. Application of impulsethermography for non-destructive assessment of concrete structures, Cement and Concrete Composites 28(4): 393401. https://doi.org/100.1016/j.cemconcomp.2006.02.011

Maierhofer, C.; Arndt, R. W.; Röllig, M. 2007. Influence of concrete properties on the detection of voids with impulsethermography, Infrared Physics \& Technology 49(3): 213217. https://doi.org/10.1016/j.infrared.2006.06.007

Maldague, X. P. V. 2001. Theory and practice of infrared technology for nondestructive testing. New York, NY: Wiley \& Sons, Inc.
Malhotra, V. M.; Carino, N. J. 2004. Handbook on nondestructive testing of concrete. $2^{\text {nd }} \mathrm{ed}$. Boca Raton, Florida, USA: CRC Press.

Meola, C.; Dimaio, R.; Roberti, N.; Carlomagno, G. M. 2005. Application of infrared thermography and geophysical methods for defect detection in architectural structures, Engineering Failure Analysis 12(6): 875-892. https://doi.org/10.1016/j.engfailanal.2004.12.030

Milovanović, B. 2013. Application of infrared thermography for defect characterization in reinforced concrete: $\mathrm{PhD}$ thesis. University of Zagreb.

Parvataneni, R. 2009. Principal component thermography for steady thermal perturbation scenarios: Master of Science thesis. Clemson University.

Ringermacher, H. I.; Mayton, D. J.; Howard, D. R.; Cassenti, B. N. 1998. Towards a flat-bottom hole standard for thermal imaging, in D. O. Thompson, D. E. Chimenti (Eds.). Review of progress in quantitative nondestructive evaluation. New York, NY: Plenum Press. https://doi.org/10.1007/978-1-4615-5339-7 54

Weiser, M.; Röllig, M.; Arndt, R. W.; Erdmann, B. 2010. Development and test of a numerical model for pulse thermography in civil engineering, Heat and Mass Transfer 46(11-12): 1419-1428. https://doi.org/10.1007/s00231-010-0656-9

Weritz, F.; Arndt, R.W.; Röllig, M.; Maierhofer, C.; Wiggenhauser, H. 2005. Investigation of concrete structures with pulse phase thermography, Materials and Structures 38: 843-849. https://doi.org/10.1617/14299

Bojan MILOVANOVIĆ. PhD. Postdoctoral researcher at the University of Zagreb, Faculty of Civil Engineering, Department of materials. He is a member of 6 national and international professional bodies. He is a Level II thermographer, and licensed IR thermography instructor. In his scientific work he is dealing with the problems regarding energy efficiency, building physics, and non-destructive testing (primarily infrared thermography) and has published several papers on these topics. He is finished his PhD thesis titled "Application of Infrared Thermography for defect characterization in reinforced concrete". He has collaborated on several domestic and EU projects: REPUBLIC MED (Retrofitting Public Spaces in Intelligent Mediterranean Cities), CROSKILLS I Build Up Skills for Croatia (CIP Intelligent Energy Europe BUILD UP Skills initiative), Eco-Sandwich - Energy Efficient, Recycled Concrete Sandwich Facade Panel (CIP Eco-Innovations), INTENSE - From Estonia till Croatia: Intelligent Energy Saving Measures for Municipal housing in Central and Eastern European countries (Intelligent Energy Europe), From Nano to Macrostructure of Concrete, Microstructure of mineral composites containing sheep's wool. Currently, he is participating in the CROSKILLS II Build Up Skills CROatia: (IEE/13/BWI/722/SI2.680179), CA EPBD IV project as well as SEEDPass - South East Europe strategic partnership in vocational education and training in Passive House Design for nearly zero energy buildings development. He is a member of publishing board of the "CrSNDT Journal" and "International Journal of Energy Efficiency in Buildings". Mr. Milovanović published more than 70 scientific papers as an author or co-author. His research interests are IR thermography, building physics, energy efficiency and concrete technology.

Ivana BANJAD PEČUR. Prof., Head of the Department of materials and Head of Materials Research Chair and professor in the Department of materials at the University of Zagreb, Faculty of Civil Engineering. Prof. Banjad Pečur has experience in national scientific and technological projects (Energy efficiency, Special types of concrete, Prefabricated construction using MEPS concrete) and international scientific projects (CROSKILLS - Build Up skills Croatia, ECO-SANDWICH Energy Efficient, Recycled Concrete Sandwich Facade Panel, LIFE project CONWAS - Development of sustainable construction and demolition waste management system for Croatia"). She was participating in the project CA EPBD III - Concerted Action supporting transposition and implementation of Directive 2002/91/EC of the European Parliament and of the Council and its proposed recast, as expert on building physics and implementation of measures of improvement. Currently, she is participating in the CA EPBD IV project as well as SEEDPass - South East Europe strategic partnership in vocational education and training in Passive House Design for nearly zero energy buildings development. Prof. Banjad Pečur is project coordinator for CROSKILLS I, CROSKILLS II and ECO-SANDWICH projects. Prof. Banjad Pečur published more than 70 scientific papers as an author or co-author. Her research interests are IR thermography, energy efficiency, concrete technology and non-destructive testing.

Nina ŠTIRMER. Prof., Head of Materials Technology Chair and Professor at the University of Zagreb, Faculty of Civil Engineering, Department of Materials. Previously she was Head of Laboratory of materials and coordinating national scientific project "From nano to macro structure of concrete". She was senior expert in CIP Eco-innovation project RUCONBAR - Rubberized concrete noise barriers, CIP IEE project "Croskills I" and CIP Eco Innovation project "Eco-sandwich"). She was actively participating in EUREKA project "Industrial floors" and LIFE project CONWAS - Development of sustainable construction and demolition waste management system for Croatia". Currently she is an associate on the EU projects Anagennisi (FP7), CROSKILLS II, and acting as the Vice Dean for Financial Management at the University of Zagreb, Faculty of Civil Engineering. Prof. Štirmer published more than 80 scientific papers as an author or co-author. Her research interests are concrete technology and resource efficiency, recycled materials. 